\title{
Social cognition in the breadbasket: The effect of schematic information about farmers on farmers' and nonfarmers' memory for stories
}

\author{
RICHARD JACKSON HARRIS, MARK A. THOMPSON, and STACIE STOLTZ \\ Kansas State University, Manhattan, Kansas
}

Three experiments investigated farmers' and nonfarmers' perceptions about farmers and the effects of these schemata on memory for a story about a character who was or was not identified as a farmer. Experiment 1 identified dimensions on which farmers' and nonfarmers' perceptions about farmers differed significantly. This information was used to construct stories, used in Experiments 2A and 2B, about a businessman facing bankruptcy. Half of the stories described Robert in a manner consistent with the farmers' schema about farmers; the other half described him in a manner consistent with the nonfarmers' schema about farmers. Another variable, label, identified Robert as a farmer or small businessman or did not identify his occupation. The results showed several complex interactions of the subjects' schema information, the label, and the content of the story, both under conditions of immediate testing and 2 days later.

The schemata in one's memory affect both the processing of new information and the retrieval of old information from permanent memory (Alba \& Hasher, 1983; Brewer \& Nakamura, 1984; Graesser \& Nakamura, 1982; Rumelhart, 1980; Thorndyke, 1984). The present research applied schema theory to social cognition (see, e.g., Fiske \& Taylor, 1984) by identifying the prevailing schema about farmers. The first step was to assess what this knowledge is and how it differs between urban and rural people. It may be, as farmers sometimes claim, that nonfarmers hold some distorted perceptions about farmers.

The relevant schemata about farmers were identified in Experiment 1; the effects of these schemata on memory and information processing were examined in Experiments $2 \mathrm{~A}$ and $2 \mathrm{~B}$. Subjects read a story about a modern farmer in danger of losing his farm to foreclosure. Memory for this story was tested, with an eye toward determining the contribution of subjects' schema about farmers to the processing of information in that story.

\section{EXPERIMENT 1}

\section{Method}

The subjects were 146 male and female introductory psychology students at Kansas State University, a land-grant university in an agricultural area. Although the university serves the entire state and has a majority of urban and suburban students, it also draws relatively heavily from the rural areas of Kansas.

The subjects completed a series of 33 semantic differential scales used to assess stereotypes of farmers. The subjects were given a list of characteristics and their opposites and were asked to indicate on a 7-point scale the number most closely representing their perception of a typical farmer.

Requests for reprints may be sent to Richard J. Harris, Department of Psychology, Bluemont Hall, Kansas State University, Manhattan, KS 66506. Mark Thompson is now at the University of Kansas. Thanks are expressed to Lawrence Schoen and John Skowronski for helpful comments on earlier drafts of the manuscript.
Finally, they filled out a demographic questionnaire, which was used to classify each person as a farmer, nonfarmer, or intermediate.

The subjects were divided into farmer, nonfarmer, and intermediate categories according to the following criteria: (1) farmer-having lived on a farm/ranch for at least 3-5 years or having worked on a farm/ranch for several summers full-time for a year or more; (2) nonfarmer-having very little exposure to a farm/ranch setting; (3) intermediate-having some exposure to a farm/ranch setting in the form of working or living there (e.g., frequent visits to farm relatives or very short-term personal work). There were 71 nonfarmer subjects, 49 farmer subjects, and 26 intermediate subjects.

The subjects were run in groups of 15-25 and were told that the purpose of the experiment was "to test people's knowledge about and attitudes toward farmers and the profession of farming." They were told to complete the semantic differential task at their own speed.

\section{Results and Discussion}

Results from each of the 33 semantic differential scales were analyzed by a one-way analysis of variance, with three levels (farmer, nonfarmer, intermediate) of the between-subjects variable. Nine of the scales showed a significant $(p<.05)$ difference between farmers and nonfarmers; means of these scales appear in Table 1. The composite profile by the farmers was taken to be the rural schema about farmers, whereas the profile by the nonfarmers was taken to be the urban schema about farmers. These were used to construct materials for Experiments $2 \mathrm{~A}$ and $2 \mathrm{~B}$ below.

\section{EXPERIMENT 2A}

The second experiment was performed to test the effect of farmer and nonfarmer subjects' knowledge about farmers on the processing of information in a story about a man who either was or was not identified as a farmer. The basic hypothesis was that, if the character was identified as a farmer, the subjects' farmer schema should be retrieved from memory and used in guiding the accep- 
Table 1

Experiment 1: Mean Ratings of Farmers by Farmer, Nonfarmer, and Intermediate Subjects

\begin{tabular}{lccccc}
\hline & & \multicolumn{4}{c}{ Subject Type } \\
\cline { 3 - 5 } \multicolumn{1}{c}{ Scale } & Direction & Farmer & Nonfarmer & Intermediate & Mean \\
\hline Intelligence & Low to High & 5.55 & 5.08 & 5.27 & 5.27 \\
Backward-Progressive & Low to High & 5.41 & 4.56 & 4.46 & 4.83 \\
Affectionate & Low to High & 5.41 & 4.80 & 4.89 & 5.02 \\
Articulate & Low to High & 4.90 & 4.25 & 4.35 & 4.49 \\
Environmental & Anti- to Pro- & 6.41 & 5.72 & 6.12 & 6.02 \\
Country Music & Like to Dislike & 3.96 & 3.09 & 3.19 & 3.40 \\
Naivete & High to Low & 4.61 & 3.82 & 4.00 & 4.12 \\
Political Party & Democrat to Republican & 4.76 & 3.68 & 3.50 & 4.01 \\
Dress Style & Out to In & 4.18 & 3.35 & 3.39 & 3.64 \\
\hline
\end{tabular}

Note-Only scales showing significance at $p<.05$ are included.

tance of the information about that person. The constructed meaning of the story for a given subject should be a product of both the story itself and the stored knowledge (farmer schema) in the memory of the subject. To the extent that the farmer schema would differ for farmer and nonfarmer subjects, the constructed and remembered meaning of the story should also differ between the two groups.

\section{Method}

Subjects. The subjects were 203 introductory psychology students at Kansas State University. They were divided into 99 farmer subjects and 104 nonfarmer subjects according to the criteria used in Experiment 1 . In this study there was no intermediate group; in order to keep the farmers a fairly homogeneous group, subjects who would be classified as intermediate by the criteria used in Experiment 1 were classified as nonfarmers in Experiment 2A.

Materials, Design, and Procedure. The subjects read one of two stories. Depending on the condition, the story was consistent with either the rural schema or the urban schema about farmers, as assessed in Experiment 1 . The stimulus story, which was about 350 words long, was about a man who was facing bankruptcy in his business. The stories were identical except that the man in one of the stories (urban-schemaconsistent story) was described in a manner consistent with the nonfarmer schema about farmers and the man in the other story (rural-schema-consistent) was described in a manner consistent with the farmer schema about farmers.

There was a second manipulation whereby a third of the subjects were told that the man in the story was a farmer, a third were told that he was the owner of a small store, and a third were told nothing of his occupation. This information occurred in the first sentence of each story. Thus there were six stories altogether $(2$ schema consistency $\times 3$ occupational labels).

After reading the story and returning the paper to the experimenter, the subjects were given a 15 -min irrelevant interpolated task. Next, they were given a list of 38 sentences concerning the story. The items were to be rated on a 5-point scale from definitely false to definitely true. The items were of five types: (1) 9 farmer-bias items, (2) 9 nonfarmerbias items, (3) 7 control items-true, (4) 7 control items-false, and (5) 6 control items-indeterminate. The farmer-bias items were true in the story consistent with the rural schema about farmers, based on the results of Experiment 1 (e.g., "Robert is a very intelligent man," "Robert is very progressive," "Robert is a very stylish dresser"'). The nonfarmer-bias items were true in the story consistent with the urban schema about farmers, based on Experiment 1 (e.g., "Robert is a man of average intelligence," "Robert is less progressive than many others," "Robert's style of dress is somewhat dated"). The control items-true were true in all six stories, the control items-false were false in all six stories, and the control items-indeterminate were about information never mentioned in any of the stories.

In the final task of the session, subjects filled out the demographic questionnaire used in Experiment 1 and rated two manipulation-check sentences ("Robert is a farmer," "Robert owns a small store") on a 5-point scale from definitely false to definitely true.

Thus the study contained three between-subjects variables: farmer versus nonfarmer subject, rural-schema-consistent versus urban-schema-consistent story, and occupational label (farmer, smallstore owner, or no label). In addition, there was one within-subjects variable: type of test item (farmer-bias, nonfarmer-bias, control-true, control-false, and control-indeterminate).

\section{Results and Discussion}

The basic results were analyzed separately for the control (true, false, and indeterminate) and the farmer/nonfarmer-bias items. Only the latter will be discussed. Two analyses of variance were performed on the nonfarmer- and farmer-bias items: data from the two types of stories (rural- and urban-schema-consistent) were analyzed separately. Each analysis had three factors: subject type (farmer vs. nonfarmer), occupational label (farmer, small-store owner, or no label), and item type (farmeror nonfarmer-bias). Means for all cells appear in Table 2.

Table 2

Experiment 2A: Mean Responses for Farmer-Bias and Nonfarmer-Bias Items

\begin{tabular}{|c|c|c|c|c|c|c|}
\hline & \multicolumn{3}{|c|}{ Rural-Schema-Consistent Story } & \multicolumn{3}{|c|}{ Urban-Schema-Consistent Story } \\
\hline & Farmer & $\begin{array}{c}\text { Store } \\
\text { Owner }\end{array}$ & No Label & Farmer & $\begin{array}{l}\text { Store } \\
\text { Owner }\end{array}$ & No Label \\
\hline \multicolumn{7}{|c|}{ Farmer Subjects } \\
\hline $\begin{array}{l}\text { Farmer-Bias Items } \\
\text { Nonfarmer-Bias Items }\end{array}$ & $\begin{array}{l}4.12 \\
2.02\end{array}$ & $\begin{array}{l}3.98 \\
2.07\end{array}$ & $\begin{array}{l}4.10 \\
2.01\end{array}$ & $\begin{array}{l}1.83 \\
4.44\end{array}$ & $\begin{array}{l}1.84 \\
4.21\end{array}$ & $\begin{array}{l}1.99 \\
4.12\end{array}$ \\
\hline \multicolumn{7}{|c|}{ Nonfarmer Subjects } \\
\hline $\begin{array}{l}\text { Farmer-Bias Items } \\
\text { Nonfarmer-Bias Items }\end{array}$ & $\begin{array}{l}3.70 \\
2.25\end{array}$ & $\begin{array}{l}3.99 \\
2.09\end{array}$ & $\begin{array}{l}3.96 \\
2.00\end{array}$ & $\begin{array}{l}2.17 \\
4.07\end{array}$ & $\begin{array}{l}1.67 \\
4.43\end{array}$ & $\begin{array}{l}1.79 \\
4.33\end{array}$ \\
\hline
\end{tabular}

Note-1 = definitely false, $5=$ definitely true. 
The analysis of the rural-schema-consistent story data showed only one significant effect, the item-type main effect $[F(1,95)=425.18, p<.001]$, reflecting the fact that farmer-bias items were rated as true more than the nonfarmer-bias items (means $=3.98$ and 2.08 , respectively). This is not surprising, since the farmer-bias items were much more true in this story than were the nonfarmerbias items.

The analysis of the urban-schema-consistent story data showed a somewhat different pattern. As expected, the item-type main effect was significant $[F(1,95)=600.12$, $p<.001$; means $=1.90$ and 4.25 for farmer- and nonfarmer-bias items, respectively]. However, there was also a significant three-way interaction of subject type, label, and test item type $[F(2,95)=3.69, p<.03]$. The right-hand half of Table 2 illustrates the source of this effect. In terms of the label manipulation, in none of the four subject type $\times$ item type sets of means did the cell mean of the small-store-owner label group significantly differ from that of the no-label group (this is also true for the rural-schema-consistent story). In several cases, however, the cell mean for the farmer-label group differed from the other two means, and this pattern differed across the two subject groups. Although the pattern of responses for the farmer- versus nonfarmer-bias items was the same across farmers and nonfarmers (i.e., much more highly true responses to nonfarmer- than to farmer-bias items), this pattern was not the same across the three labels. Giving subjects the information that Robert was a farmer thus had different effects on the two groups of subjects.

On the one hand, for the nonfarmer-bias items, the farmer label lowered the truth value for the nonfarmers and raised it for the farmers (4.07 vs. 4.44$)$. Thus, the farmer subjects seemed to be drawing upon their schemata about farmers in remembering this story in which the protagonist was labeled as a farmer. Although the urban-schema-consistent story was not completely consistent with the schema that farmers hold about farmers, neither is it sharply inconsistent; thus, it is credible that the farmer subjects could, perhaps unknowingly, use this schema in remembering the story. The high cell mean (4.44) for farmer subjects, farmer label, nonfarmer-bias test items suggests such an interpretation.

On the other hand, for the nonfarmer subjects, the farmer label had the effect of raising the truth value of the responses to the farmer-bias items (2.17), relative to the store-owner and no-label conditions (1.67 and 1.79, respectively). This was not expected and is not really explainable, since those items were consistent with the farmers', not the nonfarmers', schema about farmers.

Two three-way analyses of variance were performed on the responses to the two manipulation-check sentences ("Robert is a farmer," "Robert owns a small store"). In each case the factors were subject type, label, and schema consistency (rural or urban). The analyses confirmed the effectiveness of the label manipulation: subjects who had been told either that Robert was a farmer or that he was a small-store owner usually remembered the story that way. In the no-label condition, farmers were much more likely than nonfarmers to infer that Robert was a farmer, regardless of which schema the story was consistent with. For the store-owner question, all means for the no-label cells were close to the midpoint of 3, except for the farmer, rural-schema-consistent story cell, which was consistently lower.

\section{EXPERIMENT 2B}

It is possible that no greater differences between groups in Experiment 2A were observed because of the very short interval between study and test. For this reason, Experiment 2B partially replicated Experiment 2A, but tested memory 2 days later instead of immediately after presentation of the story. Because the major interest was in the effect of the farmer label, only two of the six stimulus stories from Experiment 2A were used: the rural-schemaconsistent and urban-schema-consistent farmer-label versions. Neither the small-store-owner nor the no-label stories were used.

\section{Method}

The subjects were 95 students from the same subject pool as was used in the previous two experiments. They were classified as farmers or nonfarmers according to the criteria used in Experiment 2A. For purposes of analysis, the data were combined with the data from the farmerlabel groups in Experiment $2 \mathrm{~A}$, so that the analyses were performed on data from 59 farmers and 105 nonfarmers.

The procedure was exactly the same as in Experiment 2A, except that the test was given 2 days after presentation of the story. Subjects read the story and performed $15 \mathrm{~min}$ of the unrelated task used in Experiment $2 \mathrm{~A}$. When they returned 2 days later, they took the memory test over the story and filled out the demographic questionnaire.

\section{Results and Discussion}

Responses in Experiment 2B were analyzed, along with the data from the farmer-label groups in Experiment 2A, by a four-way analysis of variance with independent variables of delay (immediate or 2-day), farmer versus nonfarmer subject, schema consistency of the story (rural or urban), and test item type (farmer- or nonfarmer-bias). Results showed four significant effects. There was a main effect of schema consistency $[F(1,153)=5.04, p<.03]$, with responses after reading the urban-schema-consistent story being somewhat more true than those after reading the rural-schema-consistent story. Second, there was a main effect of item type $[F(1,153)=5.42, p<.022]$, with nonfarmer-bias items answered more true than farmer-bias items. Third, there was a schema consistency $X$ item type interaction $[F(1,153)=478.10, p<.0001]$, reflecting the fact that farmer-bias items were true in the rural-schema-consistent story and false in the urban-schema-consistent story, while the reverse was true for the nonfarmer-bias items, thus confirming that subjects still had good memory for the story 2 days later.

The final significant effect was the three-way interaction of farmer versus nonfarmer, schema consistency, and item type $[F(1,153)=11.69, p<.001]$. The means contributing to this interaction appear in Table 3 . The fact that 
Table 3

Experiments 2A and 2B: Mean Responses for Farmer-Bias and Nonfarmer-Bias Items (Farmer-Label Condition Only)

\begin{tabular}{lcc}
\hline & Rural-Schema-Consistent Story & Urban-Schema-Consistent Story \\
\hline & Farmer Subjects & \\
Farmer-Bias Items & 4.08 & 1.94 \\
Nonfarmer-Bias Items & 2.06 & 4.31 \\
Mean & 3.08 & 3.13 \\
& Nonfarmer Subjects & \\
Farmer-Bias Items & 3.72 & 2.30 \\
Nonfarmer-Bias Items & 2.35 & 4.03 \\
Mean & 3.03 & 3.16 \\
\hline
\end{tabular}

farmers, more than nonfarmers, rated the farmer-bias items more true after the rural-schema-consistent story and nonfarmer-bias items more true after the urban-schema-consistent story, and that they rated the other two types of items more false than nonfarmers rated them, indicates that farmers in general performed the task better than nonfarmers; that is, they remembered the material better. The expected effect of the schema information in memory did not occur.

No main effects or interactions involving delay were significant at the .05 level. Thus, the predicted greater effect of schema information over time was not observed.

\section{GENERAL DISCUSSION}

The present experiments empirically identified several components of farmers' and nonfarmers' schemata about farmers and showed some evidence for effects of this knowledge on memory. However, the evidence was less strong than expected. There may be several reasons for this. The farmers' and nonfarmers' schemata may not have differed from each other substantially enough to produce predicted results. Although the farmers' schema about farmers was fairly well-defined, the nonfarmers' schema about farmers was less so. For example, farmers believed farmers to be highly intelligent; nonfarmers believed farmers to be slightly above average in intelligence, but less intelligent than they were rated by the farmers.

A second reason has to do with the fact that farmers showed better memory overall than did nonfarmers, especially in Experiment 2B. This difference occurred only with the farmer- and nonfarmer-bias items, however, and not with the control items, thus arguing against a generally more capable performance by the farmers. The farmers may have done better on the bias items because the story was about a farmer, and thus was easier for these subjects to relate to their own experience. The fact that this farmer advantage did not occur in Experiment 2A, in which only one third of the subjects identified Robert as a farmer, tends to support this conclusion.
A third reason that Experiments $2 \mathrm{~A}$ and $2 \mathrm{~B}$ did not obtain stronger effects of schema information could be that even the retention interval of 2 days used in Experiment 2B was too short to clearly demonstrate the biasing effect in memory of schemata that differed only modestly.

A fourth possible reason for the failure to obtain an effect of schema over time is that the subject population was from a land-grant university with a general emphasis on agriculture. Thus even the nonfarmers may have held more accurate schemata about farmers than their nonfarmer counterparts elsewhere in the country. Indeed, many of the nonfarmers in the present experiments were lifelong residents of small towns in rural areas. In Kansas even the big-city dwellers of Kansas City, Wichita, or Topeka are often quite knowledgeable about agriculture. The fact that several significant effects were obtained in the present experiments, even with these possible constraints of the subject population, suggests that social cognition about farmers may be an interesting and workable schema for use in further research.

\section{REFERENCES}

Alba, J. W., \& Hasher, L. (1983). Is memory schematic? Psychological Bulletin, 93, 203-231.

BreWER, W. F., \& NAKAMURA, G. V. (1984). The nature and function of schemas. In R. S. Wyer \& T. K. Srull (Eds.), Handbook of social cognition. Hillsdale, NJ: Erlbaum.

FISKE, S. T., \& TAYLOR, S. E. (1984). Social cognition. Reading, MA: Addison-Wesley.

Graesser, A. C., \& NAKamUra, G. V. (1982). The impact of a schema on comprehension and memory. In G. H. Bower (Ed.), The psychology of learning and motivation (Vol. 16). Hillsdale, NJ: Erlbaum.

RumelharT, D. E. (1980). Schemata: The building blocks of cognition. In R. J. Spiro, B. C. Bruce, \& W. F. Brewer (Eds.), Theoretical issues in reading comprehension. Hillsdale, $\mathrm{NJ}$ : Erlbaum.

ThORNDYKE, P. W. (1984). Applications of schema theory in cognitive research. In J. R. Anderson \& S. M. Kosslyn (Eds.), Tutorials in learning and memory. San Francisco: W. H. Freeman.

(Manuscript received for publication December 21, 1986.) 